\title{
Cometh Atin Ghosh, Cometh the Era of Real War against Malaria and Dengue
}

\author{
Debashis Biswas \\ Vector Control Department, Kolkata Municipal Corporation, 149 AJC Bose Road, Kolkata- 700014 \\ West Bengal, India
}

\begin{abstract}
To conquer malaria and dengue in Kolkata, India, Atin Ghosh - Member of the Mayor-inCouncil (Health and Engineering) of Kolkata Municipal Corporation - undertook several unprecedented initiatives during 2010-2013. He set up a mosquito research laboratory, allowed entomologists to work independently, formed 21 vector surveillance teams (read rapid action teams), opened five dengue detection centres, established intersectoral coordination, brought in notable changes in the tack of campaigning against mosquito-borne ailments and strengthened disease surveillance system. His efforts have yielded outstanding results. The number of malaria cases here came down to 15,656 with no death in 2013 from 1,03,236 cases with one death in 2010. Reduction in the number of dengue cases has been from 1852 cases with 2 deaths in 2012 to 238 cases with no death in 2013. To destroy Culex larvae, Mr Ghosh's department has been doing larvicidal spray along different sewerage canals of the city by using small rowing-boats as transport since 2011 on his instructions. Political leaders and the controlling health officials of different municipal corporations and states of India - who are yet to contemplate waging a real war against mosquito-borne diseases - may find this paper an eye-opener for them.
\end{abstract}

KEYWORDS: Atin Ghosh, dengue, Kolkata, malaria, political will

\section{INTRODUCTION}

Malaria is an age-old public health problem in the city of Kolkata [1]. So is dengue [2]. And the onus of preventing transmission of a mosquito-borne disease rests solely with the health department of Kolkata Municipal Corporation (KMC). In June 2010, a 12-year-old political party won the civic election and formed the board of KMC. Atin Ghosh - a 52-year-old proactive and very popular leader of the party - took over the charge of the KMC's health department as a Member of the Mayor-in-Council (MMIC) at the behest of the then Railways Minister and his party supremo Mamata Banerjee, now the Honourable Chief Minister of West Bengal. And lo! A new era of war against mosquito-borne diseases ushered in.

Things that had not been done by his predecessors in the past several decades was done by Atin Ghosh in a span of only 4 years (2010-2013). He has proved himself a trend-setter. Political leaders around the world - who still tend to trivialise mosquito control and other preventive activities needed to fight against mosquitoborne diseases - could learn a big lesson from this leader of Kolkata by studying some of his activities reported in this paper.

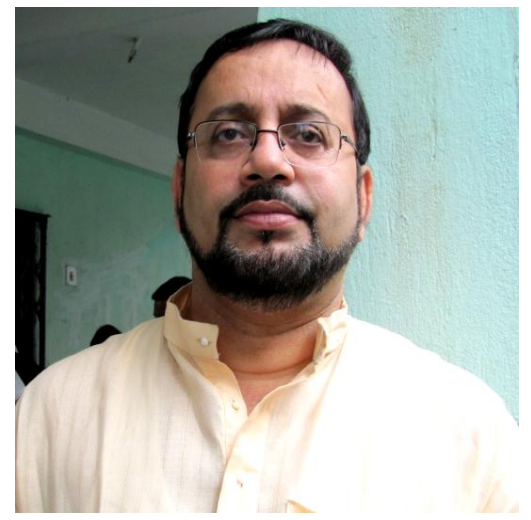

Figure 1: ATIN GHOSH, Member of the Mayor-in-Council (Health \& Engineering) of KMC. His main slogan is: "Kill mosquitoes at their source. Don't run after the flying adults." Photograph by:

BAISHAKHI BISWAS, Consultant Entomologist of KMC. 


\section{GHOSH'S MODUS OPERANDI}

During 2010-2013, Atin Ghosh undertook the following unprecedented initiatives to prevent malaria and dengue in the city of Kolkata.

\section{II.1 Entomologists Given Free Hand to Work}

There are 4 qualified entomologists in $\mathrm{KMC}$, two of them having the degrees of $\mathrm{PhD}$. One of the entomologists has been working here since 26 April 1989 and the rest 3 since 1 July 2009. Before Atin Ghosh became the MMIC (Health), none of the entomologists could work independently. There was no supporting staff for them. They could not undertake any study on mosquitoes. Tasks they used to accomplish on instructions of their seniors were not commensurate with their designation. Pertinently, vector control activities in different wards of KMC (144 in all) have been running under the administrative control of medical officers (MOs) since 1997 and the official status of a ward MO is akin to that of an entomologist. Given the situation, interfering in the activities of ward MOs was very difficult for the entomologists. Atin Ghosh was not in favour of this system. Hence he asked his department to let the entomologists fly free. The scenario changed overnight. The entomologists got the permission to monitor vector control activities independently and send reports on their findings directly to the MMIC (Health and Engineering) on a weekly basis.

\section{II.2 Mosquito Research Laboratory Established}

In August 2011, a mosquito research laboratory was set up by Mr Ghosh. This laboratory has since then been of immense help to the entomologists and all other personnel of the corporation involved in vector control. For having such in-house laboratory facilities, field workers of the department are now getting ample opportunities for training and retraining on identification of mosquito larvae and the methodologies of vector control. This R\&D wing has paved a new vista for vector control activities in Kolkata. No such mosquito research laboratory can be seen in the whole of Eastern India.

\section{II.3 Rapid Action Teams Formed}

The area of KMC is divided into 15 boroughs comprising 144 wards in all. Each borough consists of 7-12 wards. The health administration of a borough is looked after by a Borough Executive Health Officer. At wardlevel, there is one MO to steer health-related activities, including vector control, and the ward MOs are accountable to their respective Borough Executive Health Officers. Before 2010, the health department did not have any monitoring system for vector control. Atin Ghosh, a commerce graduate, felt the need for having an unbiased in-house monitoring system for vector control. He discussed this issue with the Hon'ble mayor, got a nod from him and formed 6 vector surveillance squads comprising 10-12 contractually engaged trained field workers each, and named them Central Rapid Action Teams (CRATs). These teams were formed in two phases, four CRATs in December 2010 and 2 CRATs in September 2011. In March 2013, Mr Ghosh formed additional 15 Rapid Action Teams and placed them at boroughs (@ 1 RAT per borough). His intention for forming Borough RATs was to strengthen borough-level vector control activities. Each Borough RAT comprises 6 field workers.

These 21 Rapid Action Teams - 6 CRATs and 15 BRATs - are all accountable to the entomologists. Every day, these RATs visit 1-2 wards each from 11 am to 2 pm. From 2.30 pm to 4 pm, they inspect the premises of schools, colleges, universities, hospitals, construction sites, market places, office buildings and other such important places for mosquito breeding sources. Wherever and whenever detected, they take need-based measures to destroy the mosquito larvae at once and send the information to the concerned ward health units for follow-up. From $4.30 \mathrm{pm}$ to $5 \mathrm{pm}$, the RATs record their activities in a register as per the format prepared by the entomologists. Another most important job done by a RAT is to undertake need-based vector control measures within 24 hours of the occurrence of a case of malaria or dengue anywhere in the city. A RAT can do this job very easily since the department has provided mobility support to each of the 21 RATs with a hired vehicle at the behest of Mr Ghosh. Each ward health unit of KMC remains open from 8 am to 2 pm. Hence, in case a report concerning dengue or malaria comes to the borough health office from any ward of the borough after the closure of the ward health unit, the concerned borough RAT rushes to the spot and takes required vector control measures itself since the duty hours of the RAT are from 10.30 am to 5 pm.

All the 21 RATs send their reports to the office of the entomologists (i.e. vector control department) on a regular basis, where the reports are digitalised by two data entry operators.

Crosschecking field activities apart, the RATs help the entomologists collect mosquito-related information from different wards as and when required. Before 2010, there was no supporting staff for the entomologists. 


\section{II.4 Non-medical Personnel Asked to Oversee Vector Control}

Following the instructions of Atin Ghosh, one staff at ward level and one staff at borough level have been assigned duties of overseeing vector control activities as the ward Vector Control Incharge (VCI) and borough VCI respectively.

Main duties of a Ward VCI are: 1. Collecting malaria and dengue-related information from the ward MO on a daily basis to undertake vector control measures in the affected area within 24 hours. 2. Crosschecking vector control activities in 1-2 areas of the ward per day. 3. Recording daily activities of the ward vector control workers as per the format prescribed by the entomologists. 4. Maintaining ready-stock of insecticides, knapsack sprayers and fogging machines.

Main duties of a borough VCI are: 1. Monitoring vector control activities in 1-2 wards of the borough per day. 2. Overseeing day-to-day activities of the borough RAT. 3. Mobilising the borough RAT to places for undertaking vector control measures during emergencies. 4. Preparing annual requisition of insecticides and equipment for the borough.

\section{II.5 Medical Officers Asked to Look After Patients, not Vector Control}

According to Atin Ghosh, a ward MO is a qualified doctor. Hence he will treat patients. Overseeing vector control activities cannot be his duty. In view of these, Mr Ghosh assigned these duties to a ward MO: 1. Checking staff attendance from 8 am to $2 \mathrm{pm}$. 2. Overseeing day-to-day activities of the malaria clinic located in his ward. 3. Treating patients of common ailments with medicines available to him at the ward health unit. 4 . Collecting malaria/dengue-related reports from hospitals/nursing homes/private pathological laboratories located in his ward and dispatching the same to the ward VCI for undertaking vector control measures. 5. Holding a review meeting with the laboratory technician and ward VCI everyday at $1.30 \mathrm{pm}$.

\section{II.6 Drive for Elimination of Mother Foci of Vector Mosquitoes Mounted from January}

During the dry winter season (November-February) - when the city's environment remains less conducive to the breeding of vector mosquitoes - uncovered overhead water tanks, accumulated seepage water on rooftops, water storage containers at construction sites, sumps and other such places act as the main breeding sources of Anopheles stephensi and Aedes aegypti (vectors of malaria and dengue respectively). These sources are called MOTHER FOCI of the vector mosquitoes.

According to Mr Ghosh, if we could thoroughly destroy these MOTHER FOCI during the winter season, populations of these two vector mosquitoes in Kolkata's environment will certainly remain under control during the rest of the year. In December 2010, Mr Ghosh discussed this issue with the entomologists and asked his department to undertake a city-wide drive against mosquito larvae right in January every year and continue the drive till December. Since 2011, the department has been doing the job accordingly.

\section{II.7 Workshops for Ward Councillors Organised}

Ward councillors of KMC - like their brethren in other corporations of India - too by and large are reluctant to get involved in vector control activities in their wards. Mr Ghosh is out to change their mindset. To trigger their interest about the subject, he organised two workshops for the councillors - one on 14 January 2013 and one on 11 January 2014. Experts from the Directorate of NVBDCP, Government of India, came all the way from Delhi to join these workshops as resource persons. This sort of workshop had never been organised by the health department of KMC before.

\section{II.8 Data Recording System Introduced}

In each ward of KMC, information about mosquito breeding sites detected by the concerned vector control workers - their type, addresses, measures undertaken by vector control workers for destruction of mosquito larvae, type of mosquito larvae detected (Anopheles/Aedes/Culex), etc - is now recorded on a daily basis as per the entomological format provided by the department (Table 1). Earlier, there was no such system in KMC to record vector control activities at ward-level. Who has introduced this system? He's none but Mr Ghosh himself.

\section{II.9 Indiscriminate Fogging Stopped}

Fogging with pyrethrum ( $2 \%$ extract) is a puerile exercise. The fog drives mosquitoes away; it does not kill them. Many political leaders around the country still tend to run this show just to make their voters understand that they work for the society. There was a time when fogging was a common practice in Kolkata too. The vector control squads of KMC had to undertake such measure on insistence of ward councillors. Atin Ghosh has stopped the practice. He held discussions with different ward councilors and urged them to step up only those activities which are actually needed to prevent mosquito breeding in their wards. His effort worked wonders. 


\section{II.10 Larvicidal Spray along Canals by Using Rowing-boats as Transport Introduced}

Sewerage canals in Kolkata are a big source of Culex mosquitoes. Water in these canals is filthy and stagnant. In February-March, the mosquito menace turns worst every year and the people living beside the canals suffer the problem. Edges of the canals - where mosquito larvae are found in greater numbers - are completely inaccessible to spray-workers and hence treating those canal-edges with any larvicide is literally not feasible for them, at least manually.

To address the problem, the health department of KMC started carrying out larvicidal spray along sewerage canals in March 2011 by using small rowing-boats as transport and since then, the spray has been going on. Needless to mention, this very concept too was a brainchild of Atin Ghosh. In each canal, one round of spray is completed in six days and the spray is done with an organophosphorous larvicide called Temephos $50 \%$ EC [3].

The drive has proved effective. The larval density of Culex mosquito in the canals, expressed in terms of an average number of larvae per dip, has declined remarkably. Before the commencement of the spray, the larval density used to vary from zero to 5000 . The density now varies from zero to 250 . The Directorate of NVBDCP - the country's only government agency to formulate and monitor vector-borne disease control strategies - has profusely appreciated Mr Ghosh for implementing such a noble plan to control Culex menace in Kolkata.

\section{II.11 Ward-wise Data on Potential Mosquito Breeding Sources Digitalised}

During 2013, data on permanent potential breeding sources of both malaria and dengue vectors were collected from every ward of KMC by using the format shown in Table 2. The job was done on Mr Ghosh's instructions. Inputs obtained from all the 144 wards of KMC have been digitalised. Running antivector drive in each and every vulnerable area of the city during the dry winter and hot summer seasons will now be much easier for the vector control squads of KMC for having such DATA BANK available to them. Initiative for preparing such DATA BANK concerning mosquito breeding sources has never been taken by the health authority of KMC before.

\section{II.12 Borough-level Review Meeting on Vector Control Held}

To establish a better coordination among the ward councillors and the personnel of health and other departments of KMC, Mr Ghosh convened borough-level meetings separately, spending 3-4 hours at a stretch in each borough. These meetings were held during June to August 2013.

\section{II.13 Joint Antimosquito Drive Undertaken}

To prevent vector procreation, a joint drive involving the personnel of health and the departments of solid waste management, building, drainage and water supply, has been going on in different wards of KMC since August 2010 at weekly intervals following the instructions of Mr Ghosh. The drive has immensely helped destroy both An. stephensi and Ae. aegypti larvae at construction sites, open surface drains, heaps of garbage containing various rainwater-filled discarded items such as tyres, plastic containers, teapots, bottles, coconut shells; and low-lying areas/courtyards with accumulated rainwater.

\section{II.14 Five Dengue Detection Centres Set Up for the Poor}

Blood-test done at a private pathological laboratory for dengue NS1 antigen or dengue IgM antibody costs Rs. 700 to Rs. 1200. For many people, the amount charged is beyond their reach. To help the financially weaker people of the city get their blood-test done free of cost, Mr Ghosh caused his department to establish 5 dengue detection centres (DDCs) during March-April 2011. In each DDC, blood-test for dengue is done by a most reliable method called ELISA (Enzyme-linked Immunosorbent Assay). People of Kolkata have been getting free facilities for platelet count too from different malaria clinics of KMC (140 in all) since March 2011.

\section{II.15 Patients Get Dengue-report Through an SMS Alert}

Since 12 September 2013, each DDC of KMC has been sending test reports to the patients and concerned KMC officials through an SMS alert whenever the test results are available. Relevant software has been installed in each DDC to provide this service to the city-dwellers free of cost. This information-disseminating system is comparable with the SMS info in case of bank transaction. This is a historic initiative in the field of mosquitoborne disease control programme around the world.

\section{II.16 Disease Surveillance System Strengthened}

In March 2014, one person in each ward of KMC was designated to collect daily report on malaria/dengue from different non-KMC sources such as hospitals, nursing homes and pathological laboratories located in the ward. Introduced by Atin Ghosh - this information-collecting system will help the corporation assess the city's actual 
burdens of malaria and dengue - besides aiding the corporation undertake vector control measures soon after the occurrence of a case of malaria or dengue anywhere in the city.

\section{II.17 Mass Awareness Campaigns Stepped Up}

Without community participation, preventing malaria and dengue is very tough. Having realised this, Atin Ghosh undertook a series of initiatives to increase people's awareness about these diseases. Awareness-raising campaigns mounted by his department during 2010-2013 under his stewardship are here:

- Six audio and video mobile vans were plied in KMC area for two months in 2010 - October and November.

- Multicoloured and multilingual leaflets (@ 0.5 million on malaria and 0.4 million on dengue were distributed among the people each year.

- A musical audio CD containing a beautiful song on the subject was prepared in August 2010 and played on 9 FM channels for 1-2 months each year.

- A video CD containing the same educative song was played on 10-11 popular TV channels for 2 months in 2011, one month in 2012 and one month in 2013.

- In 2011, as many as 3,25,000 copies of a multicoloured booklet on mosquito-borne diseases Bengali- 1,50,000, English- 1,00,000, Hindi- 50,000 and Urdu- 25,000) - were distributed among the students of 701 schools of the city.

- Altogether 750 multicoloured hoardings - measuring $8 \mathrm{ft} \times 6 \mathrm{ft}$ each - were put up around the city during 2013.

- 500 awareness meetings (@ 3-5 meetings per ward) involving ward councillors and local people were organised during 2013.

- Multicoloured flex banners (@ 40-140 banners per ward) were placed during 2012 and 2013 to let the city people know about the measures needed to keep malaria and dengue at bay as well as the addresses of the KMC-run malaria clinics/health centres in their wards.

- A booklet containing information about the measures needed to prevent mosquito-bites, mosquito breeding and spread of mosquito-borne ailments - together with the addresses of the KMC-run malaria clinics and dengue detection centres - was brought out in April-May 2013 in 3 different languages (Bengali, Hindi and Urdu). In all 3,00,000 copies of the booklet were distributed among the fellow-citizens through ward councillors.

- Auto-miking was done in each KMC ward for 2-3 months every year.

- In July and August 2013, messages against malaria and dengue were disseminated through electricity consumption bills issued by the Calcutta Electric Supply Corporation Limited. Around 5,00,000 people received the bills in each month.

- A first-of-its-kind documentary film of 17-minute duration was prepared by the health department of KMC in June 2013 in accordance with the guidelines provided by Mr Ghosh and the film was shown to people around the city for two months (August and September 2013) - 10 hours a day for all the 7 days of the week - using two publicity vans each fitted with a mobile LED digital screen. Measures needed to prevent mosquito breeding at various places were shown to the people through this film. Thousands of people were benefited by watching it.

- Flex-boards specifying do's and don'ts for prevention of mosquito-borne diseases were put up on 4000-5000 hired auto-rickshaws and they plied on different routes of the city in September-October every year during 2010, 2011 and 2012, covering almost all the wards of KMC.

\section{II.18 Review Meeting Held Once a Week}

Atin Ghosh does not believe in reports. He believes only his eyes and ears. Whatever he does, he does on his own. Since June 2010, he has been holding weekly meeting with all the concerned health officials of his department - including the entomologists - to review vector control activities of the department. Such meeting had never been held earlier by his predecessors. Assigning a particular job to a particular man and getting the job done by him in time is GHOSH'S WAY.

\section{RESULTS}

In 2010, the KMC and non-KMC clinics together reported 1,03,236 cases of malaria. In 2013, the figure slumped to a comfortable 15,656 . The slide positivity rate (abbreviated as SPR) declined from $28.5 \%$ in 2010 to $7 \%$ in 2013 (Table 3). In other words, nearly 23 persons per 1000 people of Kolkata became infected with malaria in 2010; the figure came down to only 3 in 2013. Decline in the number of $P f$ cases was from 15,120 in 2010 to 926 in 2013. In 2010, one person succumbed to complicated falciparum malaria in the city. The death 
occurred at a city-based hospital and the prime reason for such death was delayed hospitalisation of the patient. After 2010, no death due to malaria has occurred in the city.

The success of the KMC's health department in terms of dengue prevention and control has also been commendable. In 2012, as many as 1852 cases of dengue with 2 deaths occurred in the city. In 2013, the number of dengue cases came down to 238 with no death.

The format used by field workers in each KMC ward for recording their day-to-day activities with regard to detection and destruction of mosquito larvae is shown in Table 1. This sort of activity is rarely seen in other places around the country. By using another format, as shown in Table 2, ward-wise data on the prevalence of permanent potential mosquito breeding sources were obtained during 2013. As revealed by the survey, there are 44211 masonry tanks, 4704 open overhead water tanks, 3829 sites with accumulated seepage water under overhead water tanks, 12401 wells, 17461 open surface drains, 3115 ponds, 5202 slum clusters and 3802 under-construction buildings in the area of KMC. This DATA BANK will help the vector control squads of KMC streamline source elimination drive in different vulnerable areas of the city, especially during the winter and summer seasons.

\section{DISCUSSION}

The KMC area sprawls over 206.2 square kilometres and is inhabited by over 4.5 million people. There are 1500 slum clusters. Slum-dwellers comprise $39.4 \%$ of the city's population. The city of Kolkata is fast expanding vertically to meet people's growing need for accommodation. The city's daily floating population is around 6 million. Water storage practice among slum-dwellers is rampant.

Three meteorologically discernible seasons characterise the climate of Kolkata - the rainy season (July-October), dry winter (November-February) and moderately hot and humid summer (March-June). The city's average monthly temperature varies from $19.6^{\circ} \mathrm{C}$ in January to $30.8^{\circ} \mathrm{C}$ in April. Variation of the average monthly humidity is $61.4 \%$ in March to $83.9 \%$ in August. The city's annual rainfall varies from 1400 to 2300 $\mathrm{mm}$.

Transmission of malaria is a perennial phenomenon in the city. One to $5 \%$ of the malaria cases occur during December-June. The figure starts increasing from July (9\%) and reaches the peak either in September or October (over 20\%). The problem begins to reduce from November (14\%). Two-third of the cases $(66 \%)$ are contributed by the rainy season. Contributions of the winter and summer seasons are $21 \%$ and $13 \%$ respectively.

The prime offender is Anopheles stephensi. Breeding sources of this villainous piece are generally found in and around human-dwellings [4]. The mosquito prefers to breed more in rainwater containers than in chlorinated water containers [5]. Killing An. stephensi adults by any indoor residual spray is very tough here since the females of this vector species have changed their resting habit. Earlier, they used to rest indoors; now they do so outdoors. Killing its larvae remains the only way of reducing An. stephensi population in the city's environment. Atin Ghosh did not take much time to realise this. Hence he gave priority to vector control. "Kill mosquitoes at their source. Don't run after the flying adults" became his main slogan. But implementing such decision was very tough for him initially for some genuine reasons. Field workers of his department - the main soldiers for fighting against vector mosquitoes - were not at all oriented for doing this job. Technical skill needed for detection and destruction of mosquito larvae was abysmally lacking among them. Neither there was any scope in the health department to provide training to them.

The vector control personnel of KMC including bailiffs, multipurpose health assistants, senior field workers and field workers - who had been working in different wards under the supervision of ward MOs since 1997 - were not at all inclined to be guided by the entomologists. Field workers used to carry out larvicidal spray unknowingly. The practice was like throwing stones in the dark. Mr Ghosh turned serious and started taking measures one after another to improve this dismal scenario. By establishing a mosquito research laboratory, he helped the concerned employees develop their technical skill for vector control. Field workers and other vector control staff of his department can now identify mosquito larvae quite easily. Barring a few, they now work meticulously. Most of the vector control workers now know where to spray, what to spray, when to spray and how to spray an insecticide to destroy mosquito larvae. Staff attendance too has improved. The earlier practice of escaping duties, which was very common among the vector control personnel, has stopped, and the credit for making this entire miracle happen goes to only one man in the department and he is Atin Ghosh.

Entomologists now play the most vital role in planning and implementing vector control strategies in the city of Kolkata. Everyone in the health department of KMC now listens to them and tries to implement their advice on vector control. Ward medical officers too have begun learning about vector control from the entomologists. Field workers and other categories of vector control personnel now come to entomologists quite frequently to learn about vector biology and control.

Earlier, there was no monitoring system in the health department of KMC for vector control. The days are gone. In each ward of KMC, activities of field workers with regard to prevention of mosquito breeding are now strictly crosschecked by a BRAT. The activities of a BRAT are scrutinized by a CRAT. This sort of two- 
tier monitoring system in vector control does not exist in any other city around the world. What Mr Ghosh has done for betterment of vector control activities in the city of Kolkata is indeed brilliant!

According to Mr Ghosh, the drive for destruction of An. stephensi and Ae. aegypti larvae in Kolkata ought to start right from January every year, when the incidence of malaria cases in the city remains very low (1\%). If we could do the job religiously, the population densities of these two vector mosquitoes in Kolkata will remain well under control even during the rainy season and the times thereafter, as a sequel to which there will be less transmission of malaria in the city. In view of this, Mr Ghosh caused his department to undertake antivector drive everywhere in the city in January every year and continue it till December.

Until 2010, malaria scenario in Kolkata was annoying. The corporation-run clinics alone detected a staggering 60,000 malaria cases each year during 2000-2010, on an average. The figure involved 52,100 (86.8\%) cases of vivax malaria and 7,900 (13.2\%) cases of falciparum malaria. A total of 147 city-dwellers lost their lives to complicated falciparum malaria during 2000-2010 (average 13 deaths per year).

Since there was no system for collecting information from non-KMC sources, the health department of KMC would assess the city's malaria burden only based on case detection at its own malaria clinics. As a result, the city's actual scenario of malaria had never come to surface. To make better assessment of the problem, Atin Ghosh wrote letters to the authorities of all private pathological laboratories located in the city, urging them to send reports on cases of malaria/dengue detected at their own laboratories to the KMC on a regular basis. The effort proved effective. Reports from non-KMC sources, including government hospitals, started pouring in.

As it transpires from the Table 3, the decline in the number of Plasmodium falciparum cases was remarkable. In 2010, over 15,000 people became infected with falciparum malaria. The number of cases came down to a mere 4,500 in 2011. Clearly, the health department of KMC took only one year to slash the city's burden of falciparum malaria by a margin of $70 \%$.

The quantum of success in terms of prevention of falciparum malaria in the city was quite sparkling and this has lapped up commendable appraisal from the World Health Organization. In an alert issued to travellers in 2012, the WHO said: "The risk of falciparum malaria and drug resistance in Kolkata is relatively lower than in the other places of the state of West Bengal" [6].

The campaign tacks devised and implemented by Mr Ghosh are simply unique. Earlier, his department used to print black-and-white leaflets - either in Bengali or in Hindi or in English - and distribute them at random. People whose mother tongue was English could not read the leaflets printed in Bengali. Similarly, the Bengali-knowing people could not read the leaflets printed in English. To resolve the problem, Mr Ghosh asked his department to prepare multicoloured leaflets carrying the same 2-3 messages printed in four different languages - English, Bengali, Hindi and Urdu. The department did the job accordingly. People from every sector of the society were benefitted by reading these multilingual leaflets. The earlier practice of printing monolingual leaflets was stopped by him.

Earlier, the KMC would put up 10-15 hoardings around the city every year for publicity campaign. The number rose to 750 after the beginning of Mr Ghosh's regime. The harsh critics too now admit that the highvoltage campaign mounted by the corporation during 2010-2013 through TV, FM channels and documentary films to increase people's awareness about malaria and dengue was feasible only because Mr Ghosh was behind the programme.

Going by the authoritative reports, no entomologists are available in 25 states of India, and some entomologists are involved in the control of vector-borne diseases without supporting staff. Government initiative to recruit qualified entomologists is not yet in sight. The situation in West Bengal too is highly dispiriting. Vector-bashing programme in every district of the state (except Kolkata) still runs without entomologists. Atin Ghosh wants to change the scenario. On 20 March 2014, he wrote a letter to Malay Dey (IAS), Principal Secretary, Department of Health \& Family Welfare, Government of West Bengal, urging him to cause to develop entomologist-based infrastructure in some municipalities surrounding the area of KMC for prevention of malaria, dengue, etc. Did anyone else from KMC initiate such proposal before Atin Ghosh? No. None! And never.

\section{CONCLUSION}

Combating mosquito-borne diseases is very much possible provided there is a strong political commitment. Atin Ghosh, MMIC (Health) of KMC, has set an example. We need at least one Atin Ghosh everywhere around the country to win the yet-to-be-won battle against malaria, dengue and other mosquito-borne diseases.

\section{Acknowledgements}

Dr. Snehangshu Chowdhury, CMHO of KMC, has been trying to strengthen vector control activities in the city - an effort the author acknowledges with due respect. The author expresses his thankfulness to Dr. Basudeb Mukherjee, Dy CMHO \& MSO of KMC, for providing data on malaria and dengue. Consultant entomologists — Dr. Atanu Banerjee, Baishakhi Biswas and Bithika Mandal — encouraged me to write this paper - for which the author thank them all from the deepest core of his heart. 


\section{REFERENCES}

[1]. D. Biswas, Baishakhi Biswas, Bithika Mandal, A. Banerjee, T.K. Mukherjee, and J. Nandi, Evaluating school students' perception about mosquitoes and mosquito-borne diseases in the city of Kolkata, India, Dengue Bulletin, 35, 2011, $223-230$.

[2]. D. Biswas, Dengue resurgence (104 Diamond Harbour Road, Kolkata- 700008: Science Association of Bengal, 2007).

[3]. D. Biswas, Basics of mosquitoes (5 SN Banerjee Road, Kolkata- 700013: Information \& Public Relations Department of Kolkata Municipal Corporation, 2013).

[4]. D. Biswas, R.N. Dutta, S.K. Ghosh, S. Dey, and A.K. Hati, Breeding habits of Anopheles stephensi Liston in an area of Kolkata, Indian Journal of Malariology,29, 1992, 195-198.

[5]. Bithika Mandal, Baishakhi Biswas, A. Banerjee, T.K. Mukherjee, J. Nandi, and D. Biswas, Breeding propensity of Anopheles stephensi in chlorinated and rainwater containers in Kolkata City, India, Journal of Vector Borne Diseases, 48(1), 2011, 58-60.

[6]. WHO. International Travel and Health 2012 (PDF format). WHO-OMS-.htm; 219-20.

Table 1: Daily Report on Detection of Mosquito Larvae by the Field Workers of a Ward Health Unit of KMC

\begin{tabular}{|l|l|l|l|l|l|l|}
\multicolumn{2}{|c}{ Borough --- } & \multicolumn{2}{c}{ Ward No --- } \\
\hline $\begin{array}{l}\text { St/Rd/A } \\
\text { venue/L } \\
\text { ane }\end{array}$ & $\begin{array}{l}\text { Total no of } \\
\text { houses } \\
\text { checked }\end{array}$ & $\begin{array}{l}\text { Total no of } \\
\text { water containers } \\
\text { checked }\end{array}$ & $\begin{array}{l}\text { No of water } \\
\text { containers positive } \\
\text { for Aedes larvae } \\
\text { with addresses }\end{array}$ & $\begin{array}{l}\text { No of water } \\
\text { containers } \\
\text { positive for } \\
\text { Anopheles } \\
\text { larvae with } \\
\text { addresses }\end{array}$ & $\begin{array}{l}\text { No of water } \\
\text { containers } \\
\text { positive for } \\
\text { Culex larvae } \\
\text { with addresses }\end{array}$ & $\begin{array}{l}\text { Action taken } \\
\text { (Spray/Source } \\
\text { reduction/Release of } \\
\text { fish/Issuance of legal } \\
\text { notice u/S 496 of the } \\
\text { KMC Act, 1980) }\end{array}$ \\
\hline--- & & & --- & --- & - \\
\hline
\end{tabular}

Table 2: Addresses of Permanent Potential Mosquito Breeding Sources in KMC area Borough ---

\begin{tabular}{|l|l|l|l|l|l|l|l|l|l|l|}
\hline $\begin{array}{l}\text { Sl } \\
\text { No }\end{array}$ & $\begin{array}{l}\text { Avn/St/Rd/ } \\
\text { Lane }\end{array}$ & $\begin{array}{l}\text { Premises } \\
\text { No }\end{array}$ & MT & $\begin{array}{l}\text { Open } \\
\text { OHT }\end{array}$ & $\begin{array}{l}\text { Seepage } \\
\text { water under } \\
\text { OHT }\end{array}$ & Well & $\begin{array}{l}\text { Open } \\
\text { drain }\end{array}$ & Pond & $\begin{array}{l}\text { Slum } \\
\text { cluster }\end{array}$ & UCB \\
\hline 1 & & & & & & & & & & \\
\hline 2 & & & & & & & & & & \\
\hline 3 & & & & & & & & & & \\
\hline$\ldots$ & & & & & & & & & & \\
\hline Total & & & & & & & & & & \\
\hline
\end{tabular}

MT: Masonry tank

OHT: Overhead water tank

UCB: Under-construction building

Table 3: Malaria Scenario in KMC area

\begin{tabular}{|c|c|c|c|c|c|c|c|c|c|}
\hline Year & \multicolumn{6}{|c|}{ Case detection at KMC clinics and other health establishments } & \multirow{3}{*}{$\begin{array}{l}\text { SPR } \\
(\%)\end{array}$} & \multirow{3}{*}{$\begin{array}{l}\text { No. of } \\
\text { malaria } \\
\text { cases per } \\
1000 \\
\text { population }\end{array}$} & \multirow[t]{3}{*}{ Death } \\
\hline & \multicolumn{2}{|c|}{ KMC-run malaria clinics } & \multicolumn{2}{|c|}{$\begin{array}{l}\text { Non-KMC } \\
\text { establishments } \\
\text { (hospitals \& private } \\
\text { pathological } \\
\text { laboratories) }\end{array}$} & \multicolumn{2}{|c|}{ Grand total } & & & \\
\hline & $\begin{array}{l}\text { No of } \\
\text { Malaria } \\
\text { cases } \\
\text { detected }\end{array}$ & $\begin{array}{l}\text { No of } P f \\
\text { cases }\end{array}$ & $\begin{array}{l}\text { No of } \\
\text { malaria } \\
\text { cases } \\
\text { detected }\end{array}$ & $\begin{array}{l}\text { No of } P f \\
\text { cases }\end{array}$ & $\begin{array}{l}\text { No of } \\
\text { malaria } \\
\text { cases }\end{array}$ & $\begin{array}{l}P f \\
\text { cases }\end{array}$ & & & \\
\hline 2010 & 96693 & 14226 & 6543 & 894 & 103236 & 15120 & 28.5 & 22.7 & 1 \\
\hline 2011 & 41642 & 4200 & 2369 & 307 & 44011 & 4507 & 18.3 & 9.6 & 0 \\
\hline 2012 & 28944 & 2772 & 2828 & 470 & 31772 & 3242 & 9.0 & 6.9 & 0 \\
\hline 2013 & 13566 & 684 & 2090 & 242 & 15656 & 926 & 7.0 & 3.4 & 0 \\
\hline
\end{tabular}

